\title{
PELATIHAN LIDAH BUAYA MASYARAKAT TEBO SELATAN KELURAHAN MULYOREJO
}

\author{
Oleh: \\ Anna Noordia ${ }^{1}$, Tutut Nurita ${ }^{2}$ \\ 'Program Studi Ilmu Keolahragaan FIK Unesa \\ 2Program Studi Pendidikan Sains FMIPA Unesa \\ 1annanoordia@unesa.ac.id
}

\begin{abstract}
Abstrak
Tanaman lidah buaya banyak manfaatnya terutama bagi kesehatan tubuh. Pelatihan bertujuan untuk mendeskripsikan minat masyarakat terhadap manfaat tanaman lidah buaya. Lokasi pelatihan dilaksanakan di daerah Mulyorejo Sukun Malang yang dihadiri oleh 10 peserta. Metode pelaksanaan yaitu pengumpulan data sebelum pelatihan, memberikan informasi mengenai manfaat lidah buaya, demonstrasi membuat gel lidah buaya dan pengumpulan data akhir berupa angket setelah pelatihan. Instrumen yang digunakan berupa angket sebelum pelatihan produksi pangan dari lidah buaya dan angket minat setelah pelatihan produksi pangan dari lidah buaya. Hasil dari pelatihan menunjukan minat positif terutama dalam pelatihan produksi pangan dari lidah buaya sebesar $100 \%$.
\end{abstract}

Kata kunci : lidah buaya, kesehatan

\begin{abstract}
Aloe vera plant has many benefits, especially for the health of the body. The training aims to describe people's interest in the benefits of aloe vera. The training location was held in Mulyorejo Sukun Malang area which was attended by 10 participants. The method of implementation is the collection of data before the training, providing information on the benefits of aloe vera, demonstration making aloe vera gel and collecting final data in the form of a questionnaire after the training. The instrument used was a questionnaire before the training of food production from aloe vera and interest questionnaire after training of food production from Aloe vera. The results of the training showed a positive interest, especially in the training of food production from aloe vera by $100 \%$.
\end{abstract}

Keywords: aloe vera, health

\section{PENDAHULUAN}

Tanaman lidah buaya (Aloe vera L.) adalah jenis tanaman yang digunakan untuk menyembuhkan luka bakar, menyuburkan rambut dan merawat kulit agar tetap sehat. Pemanfaatan lidah buaya sekarang mulai berkembang dengan adanya kemajuan ilmu pengetahuan dan teknologi sebagai bahan makanan dan minuman kesehatan, bahan baku industri farmasi dan kosmetik. (Agoes, 2010). Lidah buaya merupakan komoditas pertanian yang dikembangkan dalam usaha agribisnis di Indonesia yang memiliki peluang besar. Tanaman ini biasanya dimanfaatkan masyarakat untuk obat penyubur rambut. Peningkatan ilmu pengetahuan dan teknologi mengakibatkan pemanfaatan lidah buaya semakin berkembang (Fitrina, 2012). Sekarang ini tanaman lidah buaya menjadi semakin populer karena manfaatnya yang semakin luas diketahui sebagai sumber penghasil bahan baku untuk aneka produk dari industri, kosmetik, makanan, dan farmasi (Purwaningsih, 2008).
Lidah buaya dikenal sebagai miracle plant, first aid plant atau burn plant. Tanaman lidah buaya memiliki daun berwarna hijau berlapis lilin putih. Bentuknya agak runcing seperti taji, tebal, getas, tepi daun bergerigi, atau berduri kecil. Kandungan saponin yang terdapat pada gel lidah buaya ini dapat membersihkan kotoran di wajah (www.geocities.com). Gel dari lidah buaya juga dapat membuat kulit tidak cepat kering dan kelihatan lembab. Hal ini di karenakan sifat gel lidah buaya yang mampu meresap ke dalam kulit, sehingga mampu menahan kehilangan cairan yang banyak dari dalam kulit. (Suryowidodo, 1988). Kandungan kimia alami yang terdapat di dalam lidah buaya diantaranya adalah asam amino, acemannan, enzim, lignin, mineral, mono dan polisakarida, asam salisilat, saponin, sterol dan vitamin. Vitamin C dan E pada lidah buaya dapat meningkatkan ketersediaan biologis dari nutrisi esensial dan zat yang meningkatkan kesehatan (Furnawanthi, 2004).

Daerah Tebo Selatan Mulyorejo Malang banyak tanaman lidah buaya yang terdapat di pot- 
pot tanaman. Tanaman lidah buaya hanya digunakan sebagai penghias halaman. Hasil observasi sebagian besar masyarakat tebo selatan tidak tahu jika tanaman lidah buaya banyak manfaatnya untuk kesehatan tubuh. Di daerah tersebut cocok di tanami lidah buaya karena memenuhi syarat tumbuh tanaman lidah buaya. Lidah buaya adalah tanaman yang memiliki manfaat serta mudah ditanam dan tumbuh di daerah yang berhawa panas (Arifin, 2015). Syarat tumbuh tanaman lidah buaya adalah terdapat segala unsur iklim, yaitu suhu, curah hujan, dan sinar matahari. Tanaman lidah buaya juga tahan kekeringan, dapat menyimpan air pada daunnya yang tebal, mulut daun tertutup rapat sehingga mengurangi penguapan pada musim kering. Meskipun tanaman menghendaki ditanam di tempat terbuka, tetapi di dalam ruangan yang sinar mataharinya kurang pun dapat tumbuh dengan baik. Di daerah yang bersuhu antara $28^{\circ} \mathrm{C}-32^{\circ} \mathrm{C}$, tanaman ini dapat tumbuh dengan baik. Suhu optimum untuk pertumbuhannya berkisar $16-33^{\circ} \mathrm{C}$, dan curah hujan 1.000-3.000 m3 per tahun dan musim kering agak panjang (Wahjono dan Koesnandar, 2002).

\section{METODE}

Metode pelaksanaan yaitu 1) pengumpulan data awal berupa angket sebelum pelatihan yang berupa pertanyaan dengan jawaban ya dan tidak yaitu Apakah Anda bekerja saat ini?, Apakah ratarata penghasilan Anda per bulan lebih besar dari Rp. 1.500.000,-/bulan?, Apakah Anda mengetahui manfaat lidah buaya?, Apakah Anda menggunakan lidah buaya dalam kehidupan sehari-hari?, Apakah Anda mengetahui kandungan gizi dari lidah buaya?, Apakah Anda pernah melihat produk pangan dari lidah buaya di toko/swalayan terdekat?, Apakah Anda mengetahui cara membuat produk pangan dari lidah buaya?. 2) memberikan informasi mengenai manfaat lidah buaya yaitu berupa ppt yang berisi penjelasan manfaat lidah buaya terutama gel lidah buaya merupakan bahan alami dengan fungsi penyembuh yang sangat baik, 3) demonstrasi pembuatan gel lidah buaya yang dilaksanakan tim pemateri dengan mendemonstrasikan pembuatan gel lidah buaya yaitu membersihkan tangan terlebih dahulu, memotong daun yang tumbuh di bagian luar dari daun lidah buaya, mengeluarkan resin dari daun dengan mendiamkannya di dalam wadah selama 10 menit, mengupas daun, kemudian mengorek gel dengan menggunakan sendok, mempertimbangkan mencampur gel dengan pengawet alami, menuang gel ke dalam botol kaca yang steril dan terakhir gel dapat digunakan pada permukaan kulit yang teriritasi dan 4) pengumpulan data akhir berupa angket setelah pelatihan berupa pertanyaan dengan jawaban ya dan tidak yaitu Menurut Anda, perlukah disusun pembuatan modul/handout/petunjuk produksi produk dari lidah buaya?, Apakah Anda tertarik mengikuti pelatihan/penyuluhan/pembimbingan proses produksi dari lidah buaya?, Apakah Anda tertarik dan merasa perlu diadakan pelatihan pembimbingan usaha kecil mandiri?, Setujukah Anda apabila materi manfaat lidah buaya Anda gunakan dan diterapkan guna menunjang kesejahteraan keluarga?, Apakah Anda menghendaki adanya kegiatan pelatihan dilakukan secara kuntinu?. Instrumen yang digunakan adalah berupa lembar angket sebelum pelatihan dan angket minat sesudah pelatihan

Pelatihan ini dilakukan pada masyarakat tebo selatan mulyorejo dengan jumlah peserta 10. Pelatihan bertempat di RT 05 RW 007 Tebo Selatan Kelurahan Mulyorejo Sukun Malang.

\section{HASIL DAN PEMBAHASAN}

Hasil angket sebelum pelatihan yang diberikan kepada 10 peserta. Berikut ini merupakan hasil angket sebelum pelatihan:

Tabel 1 Hasil Angket Sebelum Pelatihan Lidah Buaya

\begin{tabular}{l|c|c|}
\hline \multicolumn{1}{c}{ Pertanyaan } & \multicolumn{2}{c}{ Jawaban } \\
\cline { 2 - 3 } & Ya (\%) & Tidak(\%) \\
\hline Apakah Anda bekerja saat ini? & 50 & 50 \\
\hline $\begin{array}{l}\text { Apakah rata-rata penghasilan Anda per bulan lebih besar dari } \\
\text { Rp. 1.500.000,-/bulan? }\end{array}$ & 50 & 50 \\
\hline $\begin{array}{l}\text { Apakah Anda mengetahui manfaat lidah buaya? } \\
\text { Apakah Anda menggunakan lidah buaya dalam kehidupan } \\
\text { sehari-hari? }\end{array}$ & 100 & 0 \\
\hline $\begin{array}{l}\text { Apakah Anda mengetahui kandungan gizi dari lidah buaya? } \\
\text { Apakah Anda pernah melihat produk dari lidah buaya di } \\
\text { toko/swalayan teedekat? }\end{array}$ & 80 & 20 \\
\hline $\begin{array}{l}\text { Apakah Anda mengetahui cara membuat produk dari lidah } \\
\text { buaya? }\end{array}$ & 30 & 70 \\
\hline
\end{tabular}


Berdasarkan Tabel 1. menunjukkan peserta mengetahui manfaat tanaman lidah buaya dan menggunakan dalam kehidupan sehari-hari serta peserta sebagian besar tidak mengetahui kandungan gizi yang terdapat pada lidah buaya. Peserta biasanya menggunakan lidah buaya sebagai penyubur rambut dan belum pernah melihat produk yang terbuat dari lidah buaya di toko atau swalayan terdekat.

Data angket setelah dilaksanakan pelatihan sebagai berikut.

Tabel 2 Hasil Angket Setelah Pelatihan Lidah Buaya

\begin{tabular}{lc|c}
\hline \multicolumn{1}{c}{ Pertanyaan } & \multicolumn{2}{c}{ Jawaban } \\
\cline { 2 - 3 } & Ya (\%) & Tidak(\%) \\
\hline $\begin{array}{l}\text { Menurut Anda, perlukah disusun pembuatan modul/handout/petunjuk } \\
\text { produksi produk dari lidah buaya? }\end{array}$ & 100 & 0 \\
\hline $\begin{array}{l}\text { Apakah Anda tertarik mengikuti pelatihan/penyuluhan/pembimbingan } \\
\text { proses produksi dari lidah buaya? }\end{array}$ & 100 & 0 \\
\hline $\begin{array}{l}\text { Apakah Anda tertarik dan merasa perlu diadakan pelatihan } \\
\text { pembimbingan usaha kecil mandiri? }\end{array}$ & 100 & 0 \\
\hline $\begin{array}{l}\text { Setujukah Anda apabila materi manfaat lidah buaya Anda gunakan dan } \\
\text { diterapkan guna menunjang kesejahteraan keluarga? }\end{array}$ & 100 & 0 \\
\hline $\begin{array}{l}\text { Apakah Anda menghendaki adanya kegiatan pelatihan dilakukan secara } \\
\text { kuntinu? }\end{array}$ & 100 & 0 \\
\hline
\end{tabular}

Tabel 2 di atas menunjukkan bahwa peserta memberikan minat positif diadakannya pelatihan tentang manfaat lidah buaya dalam kehidupan. Penghasilan rata-rata peserta sebagian kurang dari 1,5 juta rupiah, sehingga peserta antusias jika lidah buaya digunakan sebagai produk yang bermanfaat dari usaha kecil mandiri guna menunjang kesejahteraan keluarga. Karena dilihat dari toko atau swalayan terdekat tidak menjual produk dari lidah buaya. Maka lidah buaya merupakan peluang bisnis karena dapat digunakan untuk produk pangan seperti sirup, kosmetik contohnya digunakan sebagai lotion dan banyak lagi manfaat lainnya.

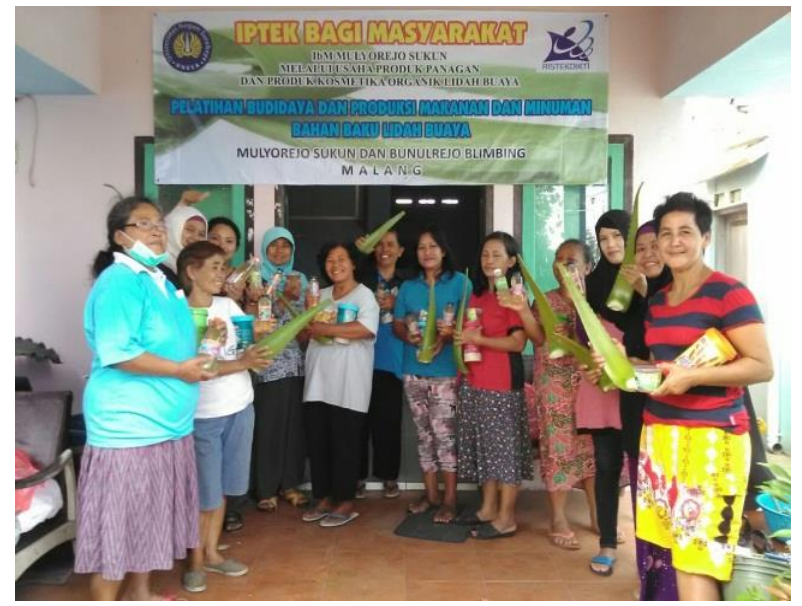

Gambar 1. Peserta pelatihan lidah buaya

\section{PENUTUP}

\section{Simpulan}

Kegiatan pelatihan lidah buaya diikuti 10 peserta dari masyarakat Mulyorejo Sukun Malang telah berhasil dan mendapatkan hasil yang baik. Hal ini ditunjukkan dari hasil angket setelah pelatihan dilaksanakan sebesar $100 \%$ peserta menyatakan ya dari pertanyaan yang diajukan menunjukkan bawa adanya minat positif pelatihan lidah buaya.

\section{Saran}

Alokasi waktu diperpanjang agar dapat menghasilkan produk yang baik terbuat dari lidah buaya.

\section{DAFTAR PUSTAKA}

Arifin, J. 2015. Intensif Budidaya Lidah Buaya Usaha dengan Prospek Yang Kian Berjaya, Yogyakarta: Pustaka Baru Press, Hal. 1-25.

Agoes, A. 2010. Tanaman Obat Indonesia. Buku III. Penerbit Salemba: Jakarta

Fitrina. F, Ali. A, dan Fitriani.S. 2012. The ratio of aloe vera and seaweed on the quality of jelly candy Jurnal IImu Pangan 13 (1): 1421

Furnawanthi, I. 2004. Khasiat dan Manfaat Lidah Buaya Si Tanaman Ajaib. Agro Media Pustaka. Jakarta. Hal 1-21 
Purwaningsih, Dyah. 2008. Prospek dan peluang usaha pengolahan produk (Aloe vera L.) Jurdik Kimia, FMIPA UNY

Suryowidodo, C.W.1988. Lidah Buaya (Aloe vera Linn) Sebagai Bahan Baku Industri. Journal Agro-Based Industri:vol5, no.2.pp:66-71

Wahjono, E. dan Koesnandar. 2007. Mengebunkan Lidah Buaya Secara Intensif. Jakarta. AgroMedia Pustaka. $59 \mathrm{~h}$ 